\title{
Stochastic Seismic Response of Super Long-Span Suspension Bridges \\ under Long Period Ground Motions
}

\author{
YAN Kun ${ }^{1,2,3, a}$, ZHU Jiajian ${ }^{1,2,3, b}$, WANG Lixin ${ }^{1,2,3, c}$, \\ JIANG Hui ${ }^{1,2,3, d}$, ZHAO Xianren ${ }^{1,2,3, e}$ \\ ${ }^{1}$ Earthquake Administration of Guangdong Province, Guangzhou 510070, China \\ ${ }^{2}$ Key Laboratory of Guangdong Province, Earthquake Early Warning and Safety Diagnosis of Major \\ Projects, Guangzhou 510070,China \\ ${ }^{3}$ Key Laboratory of Earthquake Monitoring and Disaster Mitigation Technology, Guangzhou \\ 510070, China \\ astefyk@163.com, ${ }^{b} z j j s y s u @ f o x m a i l . c o m,{ }^{c}$ wlxustc@hotmail.com,

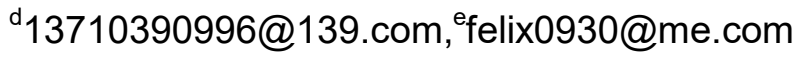

Keywords: Super-long-span suspension bridge; Long-period ground motions; Travelling wave effect; Power spectrum densities

\begin{abstract}
Long span suspension bridge has a long period of vibration, which is very sensitive to long period ground motion, so it is very important to analyze the seismic response under the long period ground motion. Taking a super long span suspension bridge as the research object, three-dimensional finite element model is established. Based on the power spectrum of long period ground motion and general ground motion, combined with the designed power spectrum, the stochastic seismic response of the suspension bridge is carried out, and the traveling wave effect of suspension bridge under long period earthquake is studied. The results show that the response power spectrum of the displacement and internal force of the suspension bridge under the long period ground motion is the maximum, and the response power spectrums under the general and designed ground motion power spectrum are very close. The seismic response of suspension bridge is reduced after the traveling wave effect is considered. The maximum mean of displacement and bending moment when the apparent velocity is $200 \mathrm{~m} / \mathrm{s}$ is about $10 \%$ lower than that of the uniform excitation.
\end{abstract}

\section{Introduction}

With the characteristics of long span and long period of natural vibration, super-long-span suspension bridge is sensitive to the long period ground motion, especially the far field earthquake. The characteristics of long period ground motion are very complex, which are affected by the factors such as source, epicentral distance and site conditions. In recent years, the case of long period of ground motion is damaged when the natural vibration period is longer ${ }^{[1-3]}$. For example, Shantou bay suspension bridge, which is about 410 kilometers from the epicenter, was still damaged in the Taiwan Chi-Chi Ms7.6 earthquake in September 21, 1999, such as the fracture of longitudinal vibration damping cable, and the non-recoverable displacement between the stiffening girder and the top of pier. The seismic damage indicates that the seismic response of the structure with long period of natural vibration needs to be further studied. This event provides a good 
evidence that long period strong ground motion has a great influence on the long span suspension bridges.

Long span bridge has a long natural vibration period, and its seismic performance has attracted the attention of scholars at home and abroad. The nonlinear seismic response of the three tower suspension bridge under traveling wave is analyzed by $\mathrm{Jiao}^{[4]}$. The seismic response of a cable stayed bridge under multiple excitations is studied by the response spectrum method ${ }^{[5]}$. Considering the height of bridge pier, the direction of excitation and the apparent wave velocity, the elastic-plastic traveling wave effect of 4 continuous girder bridges under various conditions is studied by Wang ${ }^{[6]}$. The traveling wave effect of a super long span cable-stayed bridge is analyzed by $\mathrm{Chen}^{[7]}$. Perotti ${ }^{[8]}$ investigated the non-stationary responses of multiple-supported structures. Loh and Lee ${ }^{[9]}$ studied the aseismic displacement of multi-supported bridge to multiple seismic excitations. Zerva ${ }^{[10-13]}$ has made a series of research on multi point seismic excitations of multi-span structures. Nazmy and Abdel-Ghaffar ${ }^{[14]}$ studied the seismic responses of cable-stayed bridges considering the seismic-wave traveling effect and accounted for time delay and phase difference by using the time-history method. All these studies have made significant contributions to the seismic analysis of long-span structures. However, most of these studies are based on the analysis of the standard or ordinary seismic motion, which does not take into account the influence of the ground motion and the long period ground motion.

Based on the fitting acceleration response spectrum curves of long-period seismic waves and general seismic waves established by Chen, combined with the site normalized response spectrum curve, different types of ground motion power spectral curves are obtained by iteration method. The stochastic seismic response analysis of a super long span suspension bridge is carried out, and the traveling wave effect of suspension bridge under long period earthquake is studied.

\section{The basic equation of multi point stochastic seismic response}

The structural motion equation under multi - point excitation can be expressed as ${ }^{[15]}$ :

$$
M \&(t)+C Y \mathcal{\&}(t)+K Y(t)=M \alpha E_{s}
$$

The mass, damping and stiffness matrices of the structure are presented $M, C$ and $K ; Y(t)$ is the dynamic relative displacement vector of structural system; $\alpha$ is Pseudo static modal matrix; $E_{s}$ is the inertial force indicating vector of non-support node; is seismic acceleration of structural support in the direction of seismic wave propagation.

In order to study the seismic response of structures under the excitation of multi point random earthquake, the ground motion model can be expressed in frequency domain:

$$
S(\omega)=\left[\begin{array}{cccc}
S_{11}(\omega) & C_{12}(\omega)+i Q_{12}(\omega) & C_{13}(\omega)+i Q_{13}(\omega) & \mathrm{L} \\
C_{12}(\omega)-i Q_{12}(\omega) & S_{22}(\omega) & C_{23}(\omega)+i Q_{23}(\omega) & \mathrm{L} \\
C_{13}(\omega)-i Q_{13}(\omega) & C_{23}(\omega)-i Q_{23}(\omega) & S_{33}(\omega) & \mathrm{L} \\
\mathrm{M} & \mathrm{M} & \mathrm{M} & \mathrm{M}
\end{array}\right]_{n \times \pi}
$$

In which $S_{j j}(\omega)$ is self-power spectrum; $C_{j k}(\omega)$ and $Q_{j k}(\omega)$ is real and imaginary parts of cross power spectrum respectively. Each of the excitation points can be entered as follows:

$$
S_{j k}(\omega)=S_{0}(\omega)\left(e^{-i \omega d_{j k} / V_{a}}\right)
$$

In which $S_{0}(\omega)$ is input power spectrum, $d_{j k}$ is projection distance between two excitation point $j, k$ along the direction of seismic wave propagation, $V_{a}$ is seismic wave velocity. 


\section{Finite element model of long span suspension bridge and natural vibration characteristics}

\section{Finite element model of long span suspension bridge}

Huangpu Bridge is a steel suspension bridge crossing the Pearl River. The span of main cable is $192+820+376 \mathrm{~m}$, and the rise to span ratio of main span is $1 / 10$. As shown in Figure 2 , three dimensional finite element model is established. Pylon and stiffening girder truss are simulated as spatial beam element. Main cable and hanger are simulated as only tension bar element, and geometric stiffness caused by dead load and initial tension is considered. The basic seismic intensity of the suspension bridge site is 7 degrees, and the site is classified into the following 2 categories. A $2 \%$ damping coefficient is adopted for the response calculations.

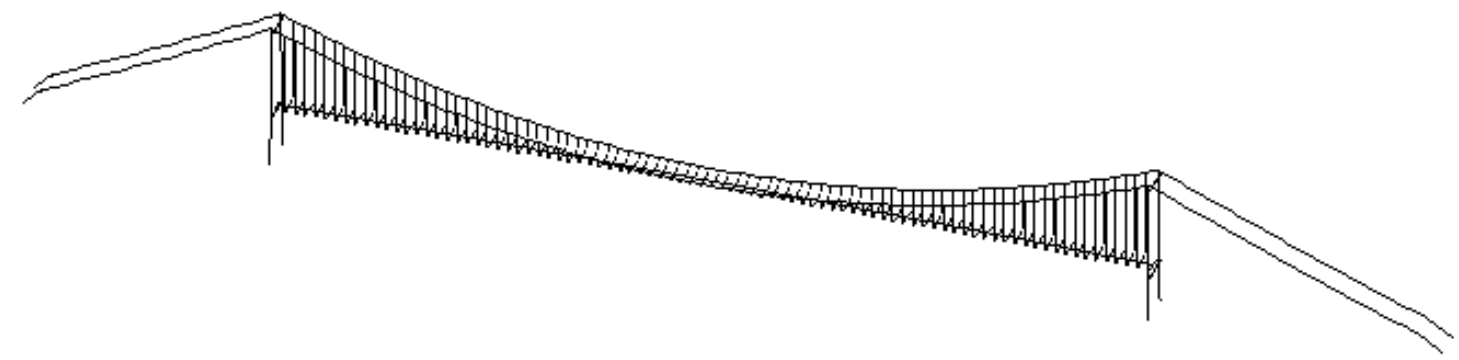

Fig.1 Three dimensional finite element model of super long span suspension bridge

\section{natural vibration characteristics}

Based on the finite element model of long-span suspension bridge, dynamic characteristics of structures is analyzed by subspace iteration method. Limited space, only part of the natural frequency and the corresponding vibration mode description are shown in table 2.It can be seen that the basic period of suspension bridge is up to $14.455 \mathrm{~s}$ which belongs to the typical long period structure, and the first 7 vibration modes are the bending vibration of the stiffening girder. The results show that the overall stiffness of suspension bridge is weak, which is consistent with the general law of dynamic characteristics of flexible structure system. The vibration mode of the suspension bridge is very concentrated, which shows the characteristics of three-dimensional and mutual coupling.

Table 1 Natural frequencies and mode shapes of suspension bridges

\begin{tabular}{cccccccc}
\hline No. & Frequency/HZ & Cycle/s & mode shapes & No. & Frequency/HZ & Cycle/s & mode shapes \\
\hline 1 & 0.069 & 14.455 & LS1 & 6 & 0.211 & 4.742 & LA1 \\
2 & 0.098 & 10.215 & LA1 & 7 & 0.234 & 4.271 & VA2 \\
3 & 0.146 & 6.846 & LA1 & 13 & 0.308 & 3.247 & T1 \\
4 & 0.149 & 6.715 & VS1 & 14 & 0.311 & 3.219 & VS2 \\
5 & 0.202 & 4.954 & VS1 & 19 & 0.360 & 2.780 & T2 \\
\hline
\end{tabular}

L-Lateral bending vibration mode of stiffening girder; V-Vertical bending vibration mode of stiffening girder; T-Torsional vibration mode of stiffened girder; S-Symmetric; A-Antisymmetric.

\section{Random seismic response analysis of the suspension bridge}

According to the geological survey report of the bridge site, soil type is soft soil, and the equivalent shear wave velocity is $168 \sim 205 \mathrm{~m} / \mathrm{s}$. In order to consider the traveling wave effect, the apparent wave velocity is taken as the shear wave velocity which is $200 \mathrm{~m} / \mathrm{s}$. Based on the power spectral density as shown in Figure 3, and the finite element model of the super long span suspension bridge as shown in figure 4 , non-uniform seismic response analysis of suspension bridge 
is analyzed by random vibration method. It is assumed that the seismic wave propagates along the longitudinal direction of the bridge (X coordinates) from the left pylon to the right.

\section{Power spectrum of displacement response}

Based on the power spectral density of different types of ground motion records, the power spectrum curve of longitudinal displacement response at the top of left pylon is given in Figure 3. It is seen that the displacement spectrum under the long period ground motion power spectrum is significantly larger than that of the general and the designed ground motion power spectrum. The spectrum results of the general ground motion power spectrum and the design ground motion power spectrum are very close. The displacement power spectrum shows two double-peak distribution, but the position of maximum peak is slightly different. The maximum peak of displacement power spectrum under the long period and designed ground motion occurs at a lower frequency (the third order vibration frequency: $0.149 \mathrm{HZ}$ ), while the maximum peak under the general ground power spectrum occurs at a higher frequency (the forth order vibration frequency: 0.202HZ).

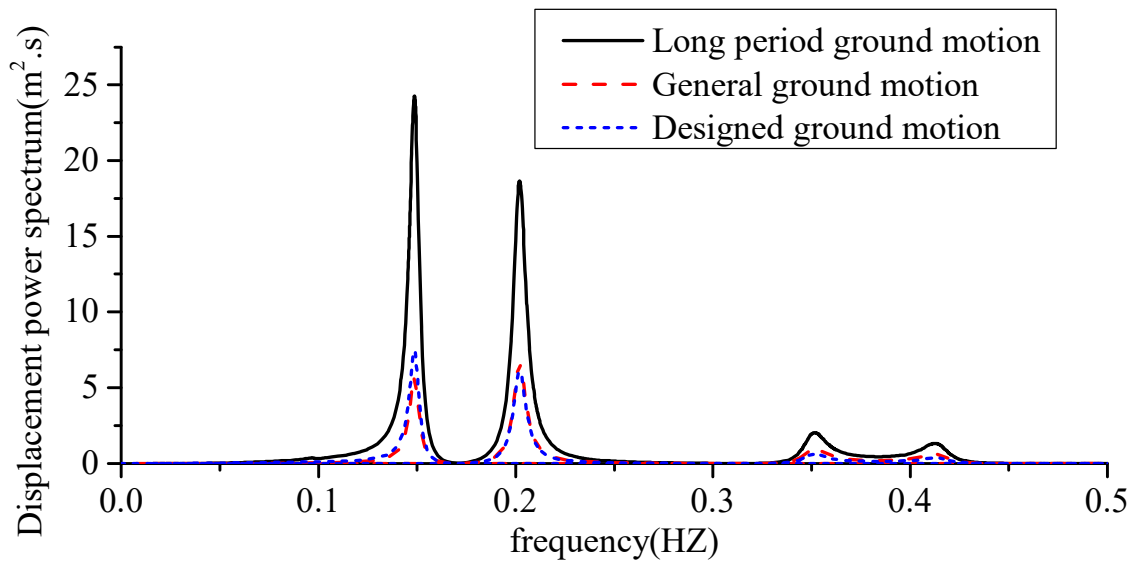

Fig.2 Longitudinal displacement at the top of the left pylon response power spectrum

\section{Maximum mean of displacement and internal force response}

In order to investigate the distribution of the maximum value of the displacement and internal force response of the super long span suspension bridge under different ground motions, the distribution of maximum mean of the longitudinal displacement and bending moment of the pylon and the stiffening girder are shown in Fig. 4 and Fig.5 respectively. Under three different types of ground motion power spectrum, the changing trend of the maximum mean is consistent, but the displacement and bending moment response under the long period ground motion power spectrum are significantly larger than that of the other two types of power spectrum, and the results of the general ground motion power spectrum and the design ground motion power spectrum are very close. 

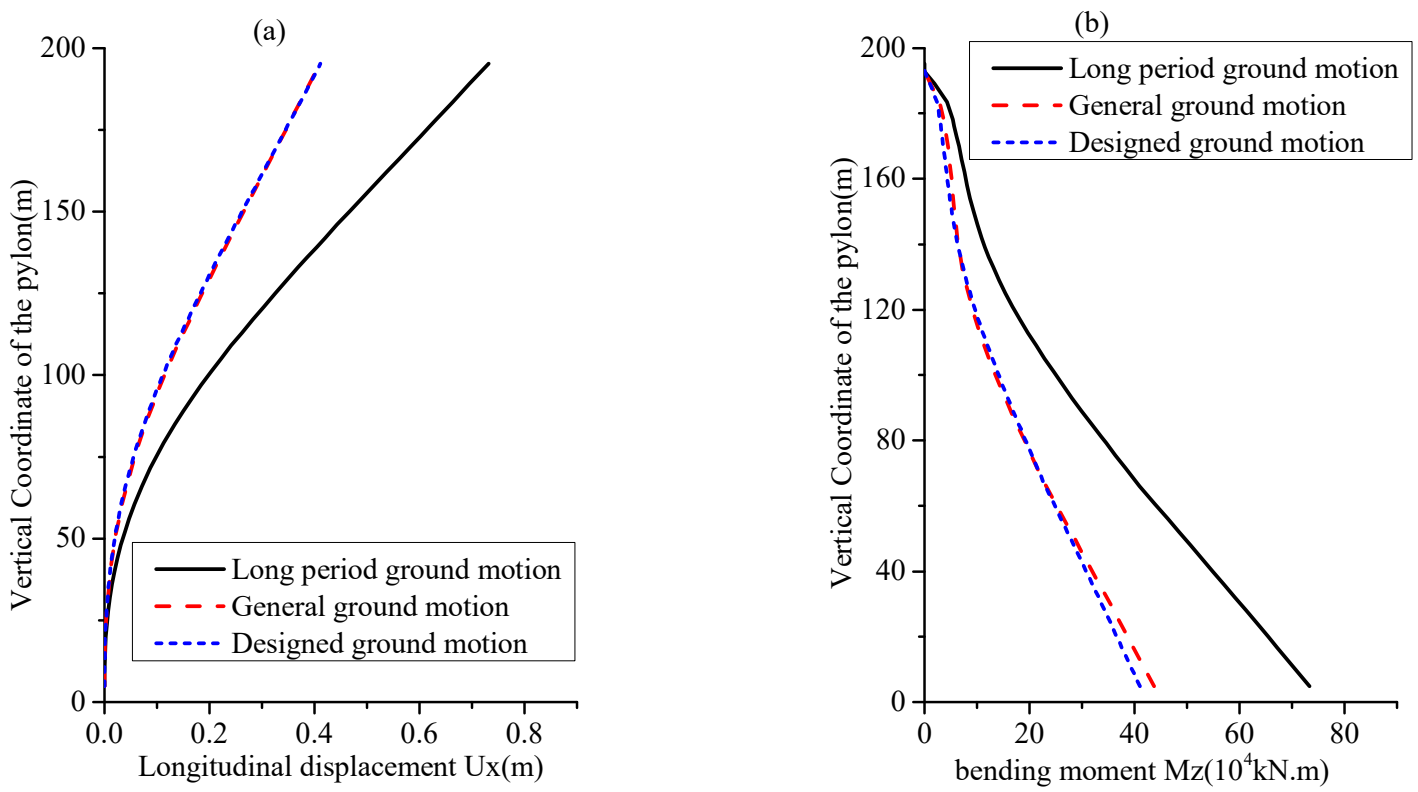

Fig.3 The maximum mean distribution of displacement and bending moment along the left pylon: (a) Longitudinal displacement Ux; (b) Bending moment Mz
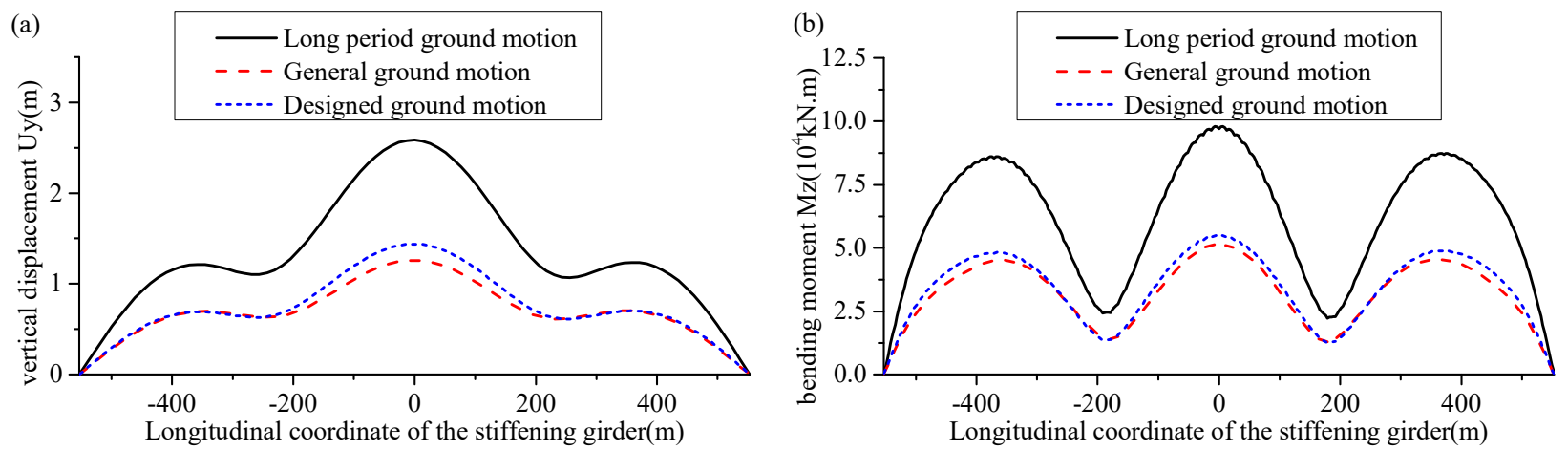

Fig.4 The maximum mean distribution of displacement and bending moment along the stiffening girder: (a) Vertical displacement Uy; (b) Bending moment Mz

\section{Effect of apparent wave velocity}

In order to further analyze the traveling wave effect of the suspension bridge under long period random earthquake, $200 \mathrm{~m} / \mathrm{s}, 1000 \mathrm{~m} / \mathrm{s}$ and infinity (i.e., uniform excitation) are selected for the apparent wave velocity. The maximum mean distribution of the left pylon and stiffening girder under the long period ground motion power spectrum are shown in Fig.6 and Fig.7 respectively. It is seen that the maximum mean of displacement and bending moment when the apparent velocity is $200 \mathrm{~m} / \mathrm{s}$ is about $10 \%$ lower than that of the uniform excitation, both the left pylon and stiffening girder. When the apparent wave velocity is $1000 \mathrm{~m} / \mathrm{s}$, the maximum mean is about $5 \%$ lower than that of the uniform excitation. The traveling wave effect has a great influence on the displacement in the middle of the stiffening girder. 

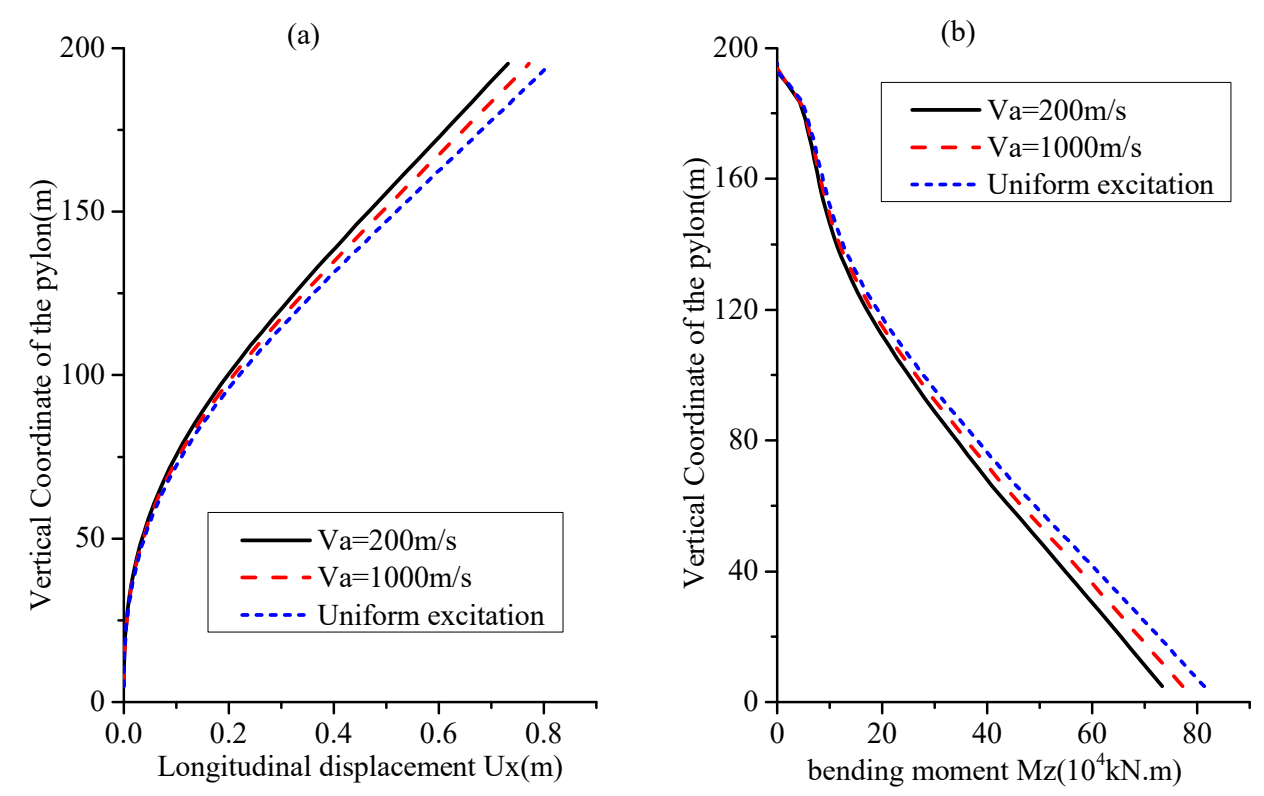

Fig.5 The maximum mean distribution along the left pylon under the long period ground motion power spectrum: (a) Longitudinal displacement Ux; (b) Bending moment $\mathrm{Mz}$
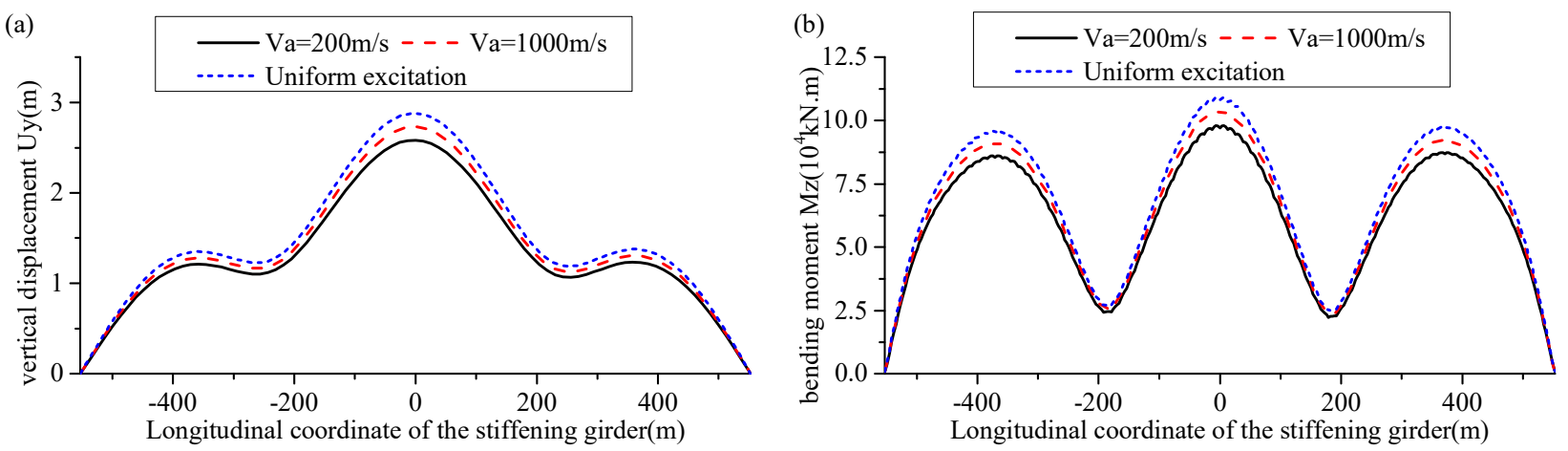

Fig. 6 The maximum mean distribution along the stiffening girder under the long period ground motion power spectrum: (a) Vertical displacement Uy; (b) Bending moment $\mathrm{Mz}$

\section{Conclusion}

This study outlines a comprehensive investigation of the stochastic response of a super long span suspension bridge subjected to long period ground motions. The long period of the ground motion is considered with the traveling wave effect. The seismic response spectrum of suspension bridge is greatly increased by the power spectrum of long-period ground motion, and the response spectrum results of the general ground motion power spectrum and the design ground motion power spectrum are very close. Traveling wave effect can reduce the seismic response of suspension bridge. Complex structures usually have smaller fundamental frequency and very closely spaced natural frequencies, and it is difficult to judge which of these will affect the structural seismic responses severely. It is difficult to make general conclusions for this complex problem. The conclusions of this paper will provide reference for the seismic analysis and design of the same type bridge.

\section{Acknowledgements}

This work is supported by the Key Science and Technology Specific Project of Guangdong Province (2012A080102008),Science and Technology Planning Project of Guangdong Province, China (2015A020217007), Science for Earthquake Resilience (XH16031), and Technology 
Foundation for Selected Overseas Chinese Scholar, Ministry of Personnel of China(2013-277), and the Construction project of Key Laboratory of Earthquake early Warning and Safety Diagnosis of Major Project, Guangdong Province (2011A060901006), and Independent Project Fund of China Earthquake Administration (CEA) Key Laboratory of Earthquake Monitoring and Disaster Mitigation Technology. Such financial aids are gratefully acknowledged.

\section{References}

[1] Koketsu K,Miyake H. A Seismological Overview of Long-Period Ground Motion. Journal of Seismology, 2008,12(2): 133-143.

[2] WANG Su-yun, YU Yan-xiang, LV Hong-shan. Study on Response Spectrum Characteristics of Long-Period Earthquake Ground Motion Using Wide Band Records From Chinese Digital Seismic Network. Seismological Journal, 1998, 20(5): 481-488.

[3] LI Chun-feng,ZHANG Yang. Urgency of the Study of Long Period Ground Motion. Seismological and Geomagnetic Observation and Research,2006,27(3): 1-8.

[4] JIAO Chang-ke, LI Ai-qun, CAO Li-lin, et a1. Traveling Wave Influence Analysis for Triple-Tower Suspension Bridges. China Civil Engineering Journal,2010, 43(12): 100-106.

[5]Allam S M,Datta T K. Analysis of Cable-Stayed Bridges under Multi-Component Random Ground Motion by Response Spectrum Method. Engineering Structures, 2000, 22(10):1367-1377.

[6]Wang J, Carr A J, Cooke N, et a1. The Response of a $344 \mathrm{~m}$ Long Bridge to Non-Uniform Earthquake Ground Motions. Engineering Structures, 2009, 31(11): 2554-2567.

[7] Chen Qingjun, Zhang Ting, Chen Zhihai et al. Traveling Wave Effect Analysis of Super-long span Cable-stayed Bridge under Long-period Stochastic Seismic Excitation. Journal of Hunan University(Natural Sciences),2014,41(4):1-9.

[8] F Perotti. Structural Response to Non-Stationary Multiple-Support Random Excitation. Earthquake Engineering \& Structural Dynamics, 1990, 19(4):513-527.

[9] CH Loh. Aseismic Displacement Analysis of Multi-Supported Bridge to Multiple Excitations. Soil Dynamics \& Earthquake Engineering, 1990, 9(1):25-33.

[10] A Zerva. Response of Multi-Span Beams to Spatially Incoherent Seismic Ground Motions. Earthquake Engineering \& Structural Dynamics, 2006, 19(6):819-832.

[11] A Zerva. Effect of Spatial Variability and Propagation of Seismic Ground Motions on the Response of Multiply Supported Structures. Probabilistic Engineering Mechanics, 1991, 6(3-4): 212-221.

[12] A Zerva. Seismic Loads Predicted by Spatial Variability Models. Structural Safety, 1992, 11(3-4):227-243.

[13] A Zerva. On the Spatial Variation of Seismic Ground Motions and Its Effects on Lifelines. Engineering Structures, 1994, 16(7):534-546.

[14] Aly S. Nazmy, Ahmed M, Abdel-Ghaffar. Effects of Ground Motion Spatial Variability on the Response of Cable-Stayed Bridges. Earthquake Engineering \& Structural Dynamics, 1992, 21(21): 1-20.

[15] Clough R W, Penzien J. Dynamics of Structures. New York: McGraw-Hill, 1993: 146-149. 